\title{
The Campus Culture Construction of University Celebration Archives
}

\author{
Liying Cui ${ }^{1, a}$, Chunling $\mathrm{Hu}^{2, b}$ \\ ${ }^{1}$ Archive of Jilin Agricultural University, Changchun, Jilin, 130118 \\ ${ }^{a}$ email, ${ }^{b}$ email
}

Keywords: Celebration Archives, Services, Campus Culture

\begin{abstract}
In celebration of University Archives as the basis to explain the role Constitution and Campus Culture Construction Services University Archives celebration, celebration archives idea how to play a better role in the construction of campus culture.
\end{abstract}

\section{Introduction}

Jilin Agricultural University ushered in the 60 birthday, the school held a grand celebration, while editing and publishing a series of development reflects the school, discipline construction, comprehensive written material of qualified personnel and rare audiovisual materials. These themes archives formed during the celebration, the celebration is called file. After finishing, the development and utilization, celebration archives played an active role in the service of campus culture construction.

School established the celebration of the Preparatory Committee, which is responsible for overall co-ordination arrangements Celebration by the Preparatory Committee responsible for the celebration archives also attach great importance to designate a person responsible for collecting, collating dossiers.

\section{The Main Content of School Celebration Archives}

During the celebration, the vast number of alumni and friends gathered Agricultural University, alumni congress, gala, special light music will, Alumni and other activities, materials celebration converging precious archives.

Archives. In celebration of the theme of the archives include: 60th anniversary preparations "briefing"; school list celebration preparations opinions about the celebration-cum-management approach and celebration organization and personnel; celebration agenda and important speech, presentation materials; guests, alumni attendance book; the Ministry of Education, the CPC Jilin Provincial Committee and other units and well-known alumni congratulatory materials; Chinese celebration networks and campus networks, "Jilin Daily", "Guangming Daily", "Chinese people" magazines about 60 anniversary celebration of Jilin Agricultural University announcement, anniversary propaganda; the 60th anniversary celebration of the preparatory Committee documents, agreements, tenders, contracts etc; 60th anniversary celebration agenda, programs, various speeches, celebration summary of the work; 60 anniversary donation list, reception work program ; alumni Forum; 60 anniversary celebration of the art of photography and painting photographic materials; round display Agricultural growth and development, the new history Museum educational achievement and alumni unveiled the completion of performance materials; celebration programs of the Academy and academic reports and other campaign materials .

Audio and video files. Celebration reflect school formed during development and changes in Celebration of the photo archives; Jilin Agricultural University, the 60th anniversary of the founding of feature films; recording anniversary since the large-scale theatrical performances, "sons of the soil" and reflect the school to commemorate the anniversary alumni disc material; moreover there are records of academic reports, forums, and celebrate the 60th anniversary of founding a series of forums material disc.

Science and Technology Archives. 500,000 words written in an informative accurate and objective "school history" and a "six rank elegance" album, set up a beautifully decorated, 
illustrated school history exhibition; burn one entitled "Earth Wife" on DVD, Gala and burn CD called "sons of the soil"; and celebrating the birthday of "newspaper magazine", "Journal of magazine" and other publications, from the multi-angle, full interpretation of the Jilin Agricultural University 60 years of arduous journey and hard work, while demonstrating the Agricultural reform and opening up 30 years of ups and downs.

Physical files. Physical archives include: Vice Premier Hui Liangyu sixtieth anniversary celebration for my school sent a congratulatory message, former Vice-Chairman of the CPPCC National Committee Wang Zhongyu, also for my school sixtieth anniversary celebration of the inscription, the Ministry of Education, Jilin Governor Han Changfu and Changchun municipal government also sixtieth anniversary celebration for my school sent a congratulatory message; the sixtieth anniversary celebration souvenir, gala performances playbill copy of a book donation certificate and the 60th anniversary celebration of documents; other universities and alumni souvenirs; foreign guests donated paintings, gift silk; sixtieth anniversary celebration theme posters; anniversary commemorative silver one; the anniversary logo and school mark.

\section{The Role of Culture and Education of Higher Anniversary Archives}

As a special cultural wealth, the anniversary of University Archives carries spiritual and cultural information over the years, the celebration comes from practice archive material and spiritual civilization construction of schools, its future school construction and development plays a very important reference. Archives celebration in much of the physical form, but from the thought process embodies the idea of a change of an era as well as colleges and universities, the spirit, and the struggle. These precious resource files after filing of our staff, upgrade, become rich in content, and there is a clear theme characteristic of the times archives cultural entity, gives an intuitive feel. It has accumulated rich humanism education colleges heritage, to inspire students to study hard, to stimulate their enthusiasm for scientific innovation, it is empty theory preaching irreplaceable, influential role in improving the quality of people.

Jilin Agricultural University, the school has a history of over half a century, in which the accumulation of 60 years formed a very deep historical resources. Ambassador archives holds 60 years of school and other aspects of materials; precious reflect the long history of Chinese and foreign academic exchanges; teaching archives, teachers and students have graduated the previous photo, enrollment form, transcript, diploma students prove stubs; reflect the school achievement award certificate; in addition, gifts celebration of domestic and foreign friends, these rich and detailed historical data, recorded 60 Ambassador of glory, reflecting the rich cultural heritage Agricultural University, school history of these files is extremely valuable intangible schools assets, is to inspire and encourage the continued momentum of college students' innovation.

Rise of the storm, a century enlightenment, the party accomplished today." Ambassador in the history of development and construction, the marshes, and the fate of the country, the nation and the times of circulation is closely related to people and things will certainly cause some college students today "In Shi Jian this "role. Therefore, we want to work as a guideline celebration archives direction, shape and inspire a new generation of talent to do business.

\section{The Method to Serve Files Celebration Campus Culture}

To achieve the celebration archives to better serve the construction of campus culture, it should be from the following aspects:

Relying Celebration, rich subject matter anniversary archives. The main purpose of the celebration is the finishing school of University culture, summed up experience in education, to further enhance the educational level. Universities anniversary is the future, the past and the milestone is hard work ahead and create brilliant new starting point, it is a source of power and achieve new development. Jilin Agricultural University, for example, by the Celebration school students to show my style, highlighting the style of the era of my school, my school Acura school achievement. Celebration fully demonstrates the level of development and the strength of running 
schools; highlight of my school teachers and students and progressive spirit; underlines our school strong organizational skills. Celebration fully demonstrated the Jilin Agricultural University, trials and hardships, tempering the vicissitudes of 60 years, fragrant peaches and plums, Fruitful sixty years of struggle. In some ways, he said collecting anniversary archives, accumulated from the reflection of the success Celebration or not. As archivists, we combine the goal of campus culture construction, effectively relying Celebration, celebration integrate the use of archival resources. Celebration archives can be combined Celebration theme to organize, to form a more systematic, full of school characteristics and profound educational file column (such as "leadership inscription", "Academic Forum", "Photo Gallery", etc.), reflect the times and radiation force.

In "cultural celebration" for the carrier, innovative way to promote its cultural archives. Celebration can pursue cultural history, witnessed a brilliant future, in different ways to promote the values and goals of the school, motivate staff and students motivated. Through a variety of ways to reproduce this advanced cultural force. (1) new students (undergraduate and graduate) school history education, by visiting the History Museum, listen to school history to explain, to understand the development process of the school. (2) the use of the school newspaper, school and other periodicals OF newspaper carried the celebration essay, photography school history, our alumni and the like; (3) through the organization of cultural exhibitions archives, the celebration of souvenirs, gifts, pictures, school badge, the school mark, inscription and other celebrities full consolidation, with appropriate instructions relating to display text, to enrich school history file; (4) the use of the campus network and modern information and communication technologies for the celebration of the full video, forums video lectures, anniversary theatrical performances, such as the establishment of digital photos unified appreciation, learning and communication platform to strengthen publicity and education efforts; (5) as other cultural activities on campus Student societies and other editorial material.

Celebration Archives active service Campus Culture. Core of the campus culture construction of university campus culture is an important ways and means of ideological and political education of college students, college students overall purpose is to develop healthy development, cultivate innovative spirit and practical ability. To this end, universities should attach great importance and give full play to the role of the Campus Culture Construction in Building Harmonious Campus. Construction of Campus Culture is a complex huge system engineering, University Archives collection management and service in one of the archives of the same responsibility in the process of construction of campus culture, the school Archives building, construction of campus culture itself is an integral part, archivists should do something, give full play to their wisdom and actively participate in the construction of campus culture. Campus culture is an important part of socialist advanced culture, so when you build all kinds of files relating to the celebration, should adhere to the correct direction of advanced culture, deeply implement the party's education policy, obedience and service centers in school work, providing school reform and development of spiritual power as the starting point, the fundamental goal of educating people, efforts to create a line with the development requirements of the times, with effective and diversified cultural celebration file system.

Use celebration archives, creating campus features spiritual culture. Archives celebration has a unique advantage in the Construction of characteristic campus culture, make full use of alumni donations physical files in a campus landscaping Characteristic Campus Culture of state and campus cultural facilities in the show efficacy. Through scientific planning, well-built, so beautiful campus cultural characteristics and tasteful was given vitality, more suitable for the developmental needs of students. Cheerful student body and mind, to cultivate their temperament, shaping their soul. Spiritual culture is the core of the campus culture, better exploitation anniversary of archival resources more quickly to the construction of campus culture has a great role in promoting: (1) the development of excellent ethos anniversary archive help development; (2) the development of archives help anniversary good style of study development; (3) the promotion of academic and cultural development of archives celebration dissemination: (4) anniversary archives patriotism education enrich a history museum. Higher anniversary of the formation of archives has its own 
uniqueness, which records the past school history and current practice, which is essential collection, which will help further expand the development and utilization of integrated services Universities Archives feature, you can enrich the cultural life of the campus theme, create a good atmosphere for education, campus culture to create distinctive.

In short, the formation of archives celebration has its own uniqueness, it can be a complete record of the history and current practice of the school, it will help to further expand the comprehensive development and utilization of services Archives school campus more abundant theme cultural life, and create a good atmosphere for education, it is possible to narrow the distance between the public and the archives, as an archivist, have a lofty sense of responsibility and a strong sense of mission, to provide quality services closely around the overall work of the school to the "progressive course of China's advanced culture" service for the purpose, so that the file can work better for the training of the new century socialist builders and successors services.

\section{References}

[1] Luo Xueling. Discussion on Campus Culture Construction of University Archives services [J]. Hubei Normal University, 20104 (147-149).

[2] Wu Huihng, Xu Jie. University Archives and Campus Culture Construction [J]. Heilongjiang Chronicles, 2008.5 (22-23).

[3] Wang Yonghua. On the role of culture in the archives of Campus Culture in the [J]. Higher Studies, 2009.6 (110-112).

[4] Deng Xiaojun. Construction History Museum archives cultural background Vocational Colleges [J]. Lantai World, 2016 No. 4 (71-72).

[5] Zhu Qinghua. How do the collection of University Archives anniversary of [J]. Lantai World, 2013 Section 14 (68-69). 